\title{
Geotechnical and geoenvironmental engineering education during the pandemic
}

Ning-Jun Jiang PhD, MASCE

Professor, Institute of Geotechnical Engineering, Southeast University, Nanjing, China; Former Assistant Professor, Department of Civil and Environmental Engineering, University of Hawaii at Mānoa, Honolulu, HI, USA (Orcid:00000001-6070-4307) (corresponding author: jiangningjun@gmail.com)

James L. Hanson PhD, PE

Professor, Department of Civil and Environmental Engineering, California Polytechnic State University, San Luis Obispo, CA, USA

Gabriele Della Vecchia PhD

Associate Professor, Department of Civil and Environmental Engineering, Politecnico di Milano, Milan, Italy

Cheng Zhu PhD, PE

Assistant Professor, Department of Civil and Environmental Engineering, Rowan University, Glassboro, NJ, USA

Yaolin Yi PhD

Assistant Professor, School of Civil and Environmental Engineering,

Nanyang Technological University, Singapore

Dali N. Arnepalli PhD

Associate Professor, Department of Civil Engineering, Indian Institute of Technology Madras, Chennai, India

Benoit Courcelles PhD

Associate Professor, Department of Civil, Geological and Mining

Engineering, Polytechnique Montréal, Montreal, QC, Canada

Jia He PhD

Associate Professor, College of Civil and Transportation Engineering, Hohai University, Nanjing, China

Suksun Horpibulsuk PhD

Professor, School of Civil Engineering, Suranaree University of Technology, Nakhon Ratchasima, Thailand; Director, Center of Excellence in Innovation for Sustainable Infrastructure Development, Suranaree University of Technology, Nakhon Ratchasima, Thailand

Menglim Hoy PhD

Lecturer, School of Civil Engineering, Suranaree University of Technology, Nakhon Ratchasima, Thailand; Fellow, Center of Excellence in Innovation for Sustainable Infrastructure Development, Suranaree University of Technology, Nakhon Ratchasima, Thailand

Akihiro Takahashi DEng, PEJp

Professor, Department of Civil and Environmental Engineering, Tokyo Institute of Technology, Tokyo, Japan
Arul Arulrajah PhD

Professor, Department of Civil and Construction Engineering, Swinburne University of Technology, Melbourne, Australia

Chih-Ping Lin PhD

Professor, Department of Civil Engineering, National Yang Ming Chiao Tung University, Hsinchu, Taiwan

Osama Dowoud PhD

Assistant Professor, Department of Civil Engineering, Istinye University, Istanbul, Turkey

Zili Li PhD

Lecturer, Department of Civil Engineering, School of Engineering, University College Cork, Cork, Ireland

Zhiwei Gao PhD

Senior Lecturer in Geotechnical Engineering, James Watt School of Engineering, University of Glasgow, Glasgow, UK

Toshiro Hata DEng

Professor, Department of Civil and Environmental Engineering, Hiroshima University, Hiroshima, Japan

Limin Zhang PhD

Chair Professor, Department of Civil and Environmental Engineering, Hong Kong University of Science and Technology, Hong Kong, China

Yan-Jun Du PhD

Professor, Institute of Geotechnical Engineering, Southeast University, Nanjing, China

Venkata Siva Naga Sai Goli MTech, SMASCE

Research Scholar, Department of Civil Engineering, Indian Institute of Technology Bombay, Mumbai, India

Arif Mohammad BE

Research Scholar, Department of Civil Engineering, Indian Institute of Technology Bombay, Mumbai, India

Prithvendra Singh MTech, SMASCE

Research Scholar, Department of Civil Engineering, Indian Institute of Technology Bombay, Mumbai, India

Ganaraj Kuntikana MTech

Research Scholar, Department of Civil Engineering, Indian Institute of Technology Bombay, Mumbai, India

Devendra N. Singh PhD, FASCE, FICE, FNAE

D. L. Shah Chair Professor for Innovation, Department of Civil Engineering, Indian Institute of Technology Bombay, Mumbai, India

This paper reports the impact of coronavirus disease 2019 on the practice and delivery of geotechnical and geoenvironmental engineering (GGE) education modules, including lectures, lab sessions, student assessments and research activities, based on the feedback from faculty members in 14 countries/regions around the world. Faculty members have since adopted a series of contingent measures to enhance teaching and learning experience during the pandemic, which includes facilitating active learning, exploring new teaching content related to public health, expanding e-learning resources, implementing more engaged and student-centred assessment and delivering highimpact integrated education and research. The key challenges that faculty members are facing appear to be how to maximise the flexibility of learning and meet physical distancing requirements without compromising learning outcomes, education equity and interpersonal interactions in the traditional face-to-face teaching. Despite the challenges imposed by the pandemic, this could also be a good opportunity for faculty members obliged to lecture, to rethink and revise the existing contents and approaches of professing GGE education. Three future opportunities namely, smart learning, flipped learning and interdisciplinary education, are identified. The changes could potentially provide students with a more resilient, engaged, interactive and technology-based learning environment. 


\section{Introduction}

The spread of the deadly infectious severe acute respiratory syndrome coronavirus 2 has led to the outbreak of the novel coronavirus disease (coronavirus disease 2019 (Covid-19)) starting from the end of 2019. It has since become unstoppable and soon reached pandemic proportions by 12 March 2020. As of 6 December 2020, there are over 65.8 million reported cases and 1.5 million deaths globally since the start of the pandemic (WHO, 2020). The Americas and Europe are the hardest-hit regions, which account for 42.6 and $30.3 \%$, respectively, of all global cases as of 6 December 2020. Covid-19 has affected almost every aspect of people's daily life, with healthcare, business, education and travel the most severely disrupted. As noted by Semaan (2020), 'we are in a chronic state of flux situated between our past experiences and an uncertain future ... They require that a lot of our attention and mental energy be spent on adjusting and renegotiating critical aspects of our lives'.

Covid-19 has caused most governments to close schools, colleges and universities temporarily around the world. According to the UN Educational, Scientific and Cultural Organization, as of 31 May 2020, more than 1.1 billion students or learners are affected by the temporary shutdown, which account for $69.4 \%$ of the total enrolled students and learners. More than 150 countries, territories or areas are imposing nationwide closure of educational institutions, enforcing students to leave campuses. Adverse social and economic consequences are being felt across communities, including interrupted learning, confusion and stress for teachers and parents unprepared for distance and home schooling, social isolation, gaps in childcare, rise in the dropout rate and so on.

As faculty members in higher-education institutions teaching and pursuing research in geotechnical and geoenvironmental engineering (GGE), the authors face even more challenges owing to the uniqueness of this discipline. GGE for long has been often viewed by students as one of the least glamorous disciplines in civil engineering. Students often found it difficult to understand explicitly the importance of subsurface conditions in constructing highway systems or building skyscrapers. Besides, large uncertainties in GGE can easily confuse and upset students as compared with other more prescribed disciplines (Wirth et al., 2017). The implicitness and uncertainty of GGE, when delivered in the traditional chalk-and-talk lecture style, have already made many students, even in normal times, conclude that learning soil mechanics, foundation engineering and geoenvironmental engineering is boring, if not outdated. Facing the outbreak of Covid-19, most courses, including GGE, now have to be taught remotely. Considering the nature of online teaching and learning, lecturers and students are facing even more challenges such as inability to augment lectures with interactive classroom activities and first-hand demonstrations. Moreover, an essential part of GGE courses, particularly at the undergraduate level, is laboratory and field sessions in which students conduct in person a series of experiments and data collection. Laboratory sessions are usually the best chance to improve participation, increase engagement and engender interests among students. Unfortunately, Covid-19 has unavoidably led to the cancellation of laboratory and field sessions in most universities and colleges.

Undergraduate and graduate courses are not the only aspects of GGE education that have been affected by Covid-19. The supervision of research students, including $\mathrm{PhD}$, master's and undergraduate students, is also being disrupted by the pandemic. In particular, the closure of research laboratories and core facilities is severely delaying the students' progress towards accomplishing their goals, particularly for those whose work is experimentally based. Under such circumstances, the biggest responsibility of supervisors and advisors is to find how to adjust research strategies to help students keep up their progress.

Although traditional GGE education is being significantly reshaped with unprecedented challenges emerging during the Covid-19 pandemic, this could also be a good opportunity for the GGE faculty to rethink and revise existing teaching content and approaches that have been conventionally followed.

In this paper, faculty members from 14 countries/regions around the world discuss in detail the disruption to GGE education during the Covid-19 pandemic as well as the implemented contingent measures. Meanwhile, future opportunities are also identified that could potentially provide students with a more resilient, engaged, interactive and technology-based learning environment.

\section{Challenges to the GGE education in universities around the world}

The outbreak of Covid-19 has significantly disrupted GGE education around the world, particularly in terms of lecture delivery, student assessment, laboratory sessions and research activities. The disruption varies in countries and regions depending on the severity of disease spread as well as control methods imposed by the local corporation and the government.

With the feedback based on GGE faculty members from 19 universities in 14 countries and regions (Figure 1), the specific challenges that they are facing and their immediate responses are ranked in terms of popularity, as shown in Figure 2. Overall, the challenge, as concurred by the faculty members, is how to maximise the flexibility of learning and meet social distancing requirements without compromising learning outcome, education equity and interpersonal interactions in the traditional face-to-face education mode.

\section{Lecture delivery}

In response to the Covid-19 outbreak, most universities around the world switch from in-person lectures to online-only or hybrid mode. This is evidenced in all 19 universities from which the authors come from. While efforts have been reported previously regarding how to create a fully online version of GGE courses (Pantazidou and Kandris, 2016), challenges are still apparent during the pandemic with the abrupt change for students, teachers 


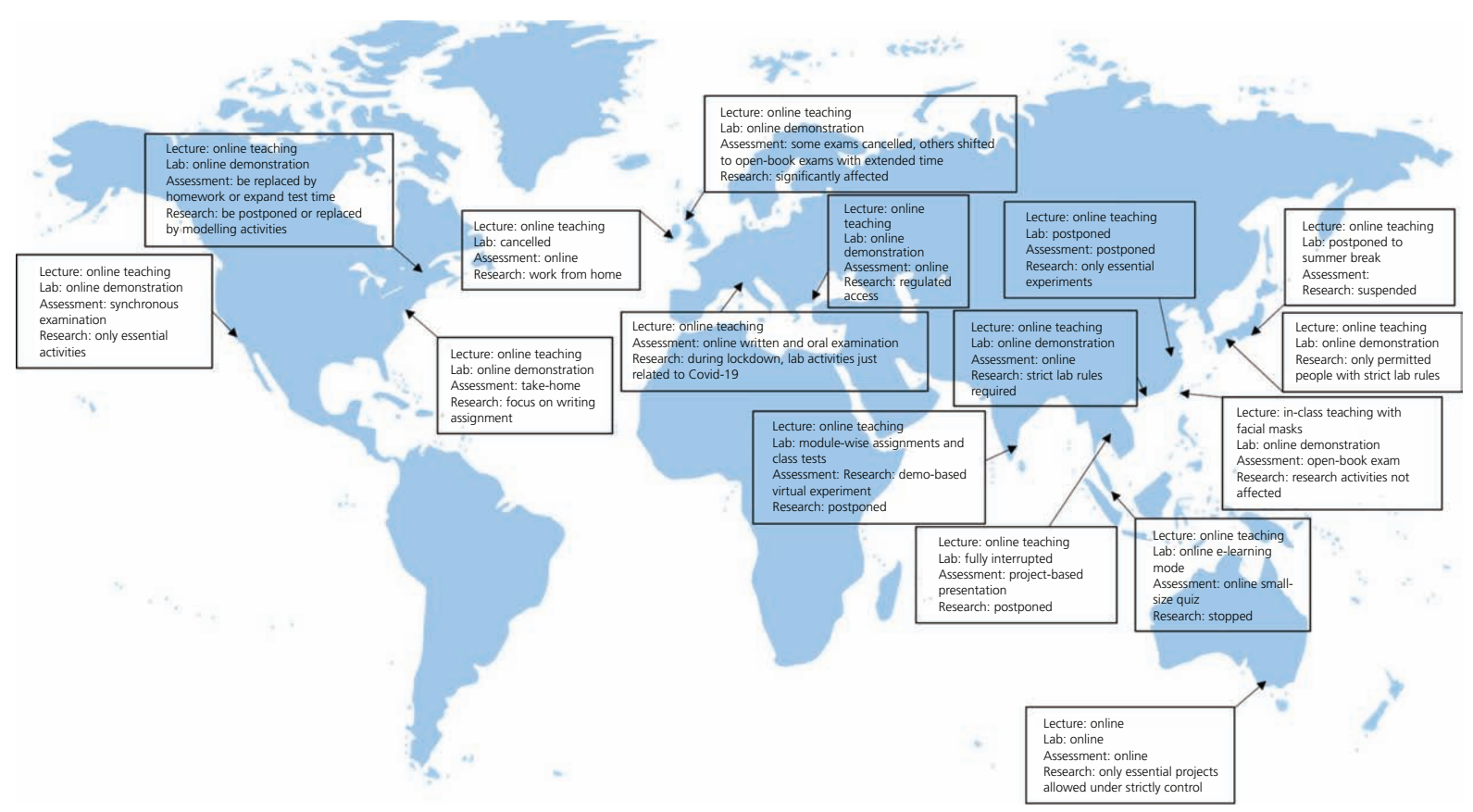

Figure 1. Summary of disruptions to geotechnical education and faculty responses around the world

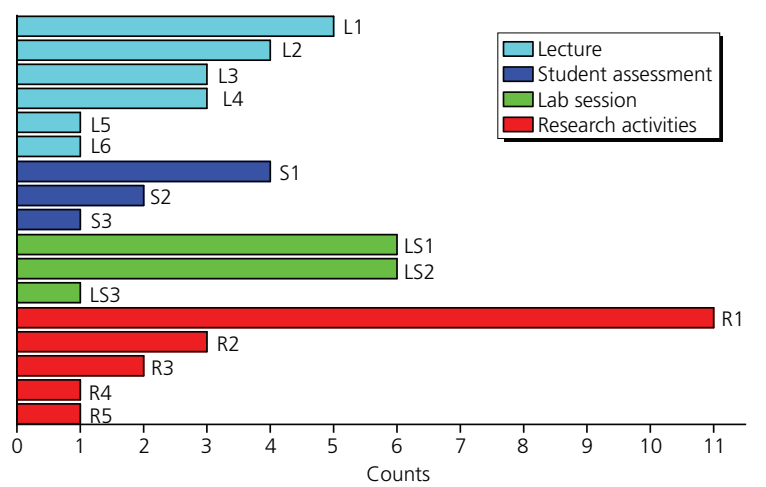

L1: availability of internet connections for online lecture 2: fulfil intact learnng outcome

L3: availability of online teaching software

L4: lack of interpersonal communication

L5: deliver contents with heavy mathematical derivations

L6: adhere to university policies

S1: equality and fairness issue when exams moved online

S2: time control and internet connectivity

S3: inaccurate assessment of student performance due to grade inflation

LS1: lack of hands-on experience for students

LS2: challenge the cofnitive abilities of examining the uncertainty and practical issue in the lab work

LS3: lack of take-home test kits

R1: limited access to experimental facilities

R2: limited faculty-student interactions

R3: uncertainty on research funding in the future

R5: limited access to on-campus high performance computing system for numerical modelling

(a)

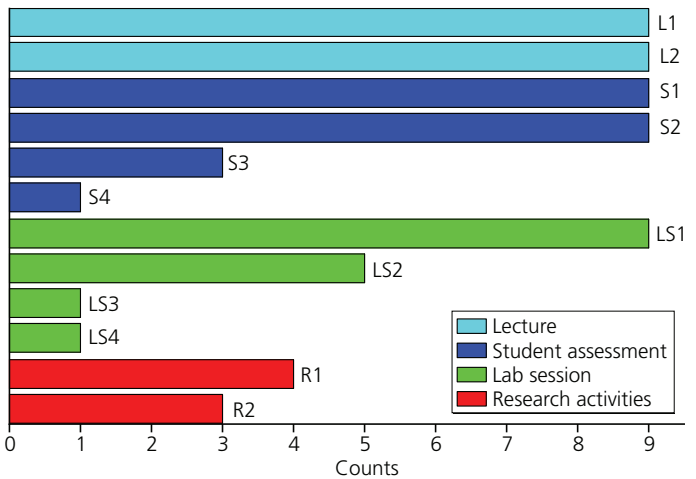

1: synchronous online lecture

L2: asynchronous lecture through pre-recording

S1: online synchronous exams

S2: open-book exams

53: project-based oral exams

54: cancellation of paper-based exams

LS1: recorded demonstrations

L2: postpone lab sessions to next semester or summer as intensive course

LS3: set-up virtual discussion forum

LS4: more group tasks for virtual lab sessions

R1: modify research plans with more focus on literature review, manuscript writing and so on

R2: maintain only essential experiment-based research activities

(b)

Figure 2. Rank of (a) challenges and (b) faculty responses in terms of lecture, lab session, student assessment and research activities

and administrators. From the students' perspective, the availability of Internet connections for the online lecture is a big concern. Apparently, not all students have access to the Internet for synchronous online lectures, and this situation is worse in less developed countries and regions. Moreover, a lack of interpersonal communication during the online learning mode could easily discourage students from learning a certain GGE course. The student-teacher in-person interactions during office hours, 
laboratory sessions, field trip or even casual time are important to shape students' perspectives about GGE, and unfortunately, these are largely missing during online learning. From the teachers' perspective, how to fulfil intact learning outcome through online teaching is no doubt the biggest challenge. The cancellation of interactive demonstrations, laboratory sessions, field trip, student group work, in-person presentation and debates is very likely to compromise learning outcome of a GGE course. For instance, for a typical environmental geotechnics course that covers environmental laws and regulations; waste materials and geotechnical engineering applications; and geotechnical management of municipal, industrial, mine and nuclear wastes, the visit to a landfill or mining site is critical for students to have a sense of the scope of geoenvironmental problems in the real world. In-person student group design assignment is also essential for them to have first-hand experience regarding the design of a geoenvironmental facility such as a landfill. Aside from the difficulty of achieving learning outcomes, teachers also face technical challenges such as how to deliver contents with heavy mathematical derivations. For instance, a geoenvironmental course related to contaminant transport involves the derivation of analytic solutions and numerical models for multiphase flow in porous media. The teaching content is highly theoretical, and students may easily become lost when it is delivered online. Finally, from the administrators' perspective, cyber-infrastructure for online teaching may not be immediately available to students and teachers after the abrupt transit to online teaching. For instance, universities may not have premium licenses of videoconferencing software such as Zoom, Google Meet and Microsoft Teams that can support the demand of the whole campus community. Moreover, universities with a low operational budget may not have enough funding to become equipped with the necessary cyber-infrastructure. Futhermore, the administrators are struggling to adhere to university policies while maintaining sufficient flexibility for lecture delivery.

\section{Student assessment}

Besides lecture delivery, how to assess students' performance in GGE courses accurately during the pandemic is another big challenge for teachers and administrators. Paper-based closedbook exams are the most common traditional student assessment method in GGE courses. However, when exams are moved online in response to the pandemic, fairness and academic honesty are hard to keep up. It is totally dependent on students' selfdiscipline, which is not always the case. If this happens, the grade is likely to be inflated, leading to overestimated assessment results. On the other hand, students may have time control and Internet connection problems during a fixed-time online exam. Considering the fact that many GGE courses involve heavy calculations, these issues are likely to lead to underestimated assessment results. Finally, the pressure from the administrators may also lead to grade inflation and overestimated assessment results. For instance, some universities have interim policies to mandate a credit/no-credit option instead of the traditional lettergrade mode or simply set a minimum passing percentage.

\section{Laboratory session}

The hands-on laboratory session is the most disrupted module in GGE courses during the pandemic. The first GGE course in most undergraduate civil engineering curricula around the world includes a significant laboratory component along with traditional lecturebased learning. Some advanced undergraduate and graduate GGE courses also include laboratory-type activities. When laboratory sessions are inevitably taught online, the learning objectives may not be efficiently met. While watching live or recorded videos of soil tests could help attain the necessary basic knowledge, the process does not challenge the cognitive skills of the students as if they were examining the uncertainty and the practical challenges in laboratory work. It also confines the unlimited varieties of test parameters and outcomes into specific ideal circumstances that cannot be generalised. Such approaches do not help realise the interaction between experiment components and processes and the consequences of errors. For instance, students can easily learn how to conduct plastic and liquid limit tests by watching recorded demonstrations. However, without real hands-on experience in the lab, it is almost impossible for students to have a sense of the soil state at these two limit water contents. It is also difficult for students to recognise the variations in Atterberg limits results obtained from different persons. The other example is that instrumentation nowadays has been more and more incorporated into advanced GGE courses. Students can easily learn the principles of various instrumentation methods from online lectures. However, without hands-on practice on how to install and calibrate sensors and collect and process data, students may not fully understand the sources of errors and uncertainties. More importantly, they lose the chance to develop professional lab skills that may be essential for their future career as geotechnical engineers. Take-home tests may be a robust alternative. However, most universities lack the necessary take-home test kits and logistics are a big issue. From the departmental or programme perspective, moving laboratory sessions online could potentially risk failing to meet accreditation requirements. For instance in the USA, the Civil Engineering Program Criteria specified by the Accreditation Board for Engineering and Technology (Abet) requires that civil engineering curricula must 'conduct experiments in at least two technical areas of civil engineering and analyze and interpret the resulting data' (Abet, 2019: p. 17). Moreover, in many universities, the lab session is a critical part of the first and perhaps the only undergraduate GGE course that students take in a civil engineering curriculum. Administration of the required hands-on laboratory component could be an important consideration for attracting undergraduate students to choose the geotechnical track in their senior year and even continue graduate studies in the same university. If delivered entirely online, the attractiveness is likely to diminish substantially.

\section{Research activities}

Research activities are an important part of both undergraduate and graduate education. With most campuses effectively closed during the pandemic, research activities, particularly those experiment-based ones, are largely halted. This is primarily due to the limited access to experimental facilities. On the one hand, the laboratory may not open 
for as long as in normal period and research groups or students have to share the limited time slots to do experiments. On the other hand, experimental facilities that require a large team to operate are not permitted to run due to restrictions on large indoor gatherings. Thus, research projects relying on these large facilities are mostly put on hold. Centrifuge tests for modelling municipal solid waste (MSW) landfill failures and large-scale shaking tables tests for evaluating seismic interactions between soil, piles and structures are two examples of this type of research that are severely impacted. In some universities, it is also reported that the on-campus high-performance computing system is partially shut down due to the lack of maintenance personnel amid the pandemic. This adversely impacts the ability to continue numerical modelling or computer vision research that requires high-performance computers. For instance, in one case, the research team has to stop their ongoing research on three-dimensional reconstruction and visualisation of an excavation site using structure-from-motion and virtual reality. In addition, faculty member-research student interactions are also negatively affected by the pandemic. While communications can still be made through videoconferencing, missing the chance to conduct experiments together or to develop sophisticated algorithms interactively is likely to be more or less hinder research progresses. Moreover, if the ongoing research work is supported by extramural funding, then the milestone delivery is likely to be delayed, particularly for industry-sponsored projects, which normally have more strict schedules. Not only for the milestone delivery in existing sponsored projects, the pandemic almost certainly brings in challenges to secure new research funding in the near future. While many national and local science and technology funding agencies see an increase in budget to support research projects related to Covid19, a significant budget cut is expected for most other research fields, including GGE. Industrial funding is also likely to shrink due to the worldwide economic slowdown. Companies are more likely to divert funding to sustain essential operations while reducing investment in research and development.

\section{Variations among universities and countries}

While many universities around the world face similar challenges to the GGE education amid the pandemic, it is worth noting that how these challenges impact the delivery of the GGE programmes is highly varied among universities and countries, due to the different structure, practices and culture of the GGE education that create unique environments for GGE students to learn and grow (DeBoer, 2012). The variations are reflected on, but not limited to, the following aspects.

- Hierarchy of engineering schools. Engineering schools vary widely in quality in different countries and regions. For instance, the engineering education quality structure is distinctly hierarchical at three levels in India (DeBoer, 2012). At the top level are the universities that have more resources to adapt swiftly to the new norm amid the pandemic and ensure uncompromised learning experience for students. However, for universities at the bottom level, they may even lack the basic cyber-infrastructure to implement remote education fully. Thus, equality in education would be lost and have severe impact on the society. On the other hand, in developed countries such as the USA, the hierarchy among research universities, undergraduate institutes and community colleges is less obvious and the public/private dichotomy is not strong. Therefore, most universities have the necessary resources and experience to cope with the challenges of the pandemic. Equal learning opportunities for students from different higher-education institutions are more likely to be maintained.

- Theoretical against practical curriculum. Whether the GGE curriculum focuses more on theory or practice highly depends on the cultural structure of a specific country or region. For instance, in many European countries such as the UK, they have a long tradition to deliver GGE courses with a strong emphasis on theoretical components and focus on scientific training of advanced theorists. Their curricula include fewer lab sessions, field trips and connections to the industry. Some countries have more balanced curricula. For example, GGE programmes in the USA and China are oriented towards both theoretical and hands-on learning inputs. In other countries such as India, however, the curriculum is highly practical and aims to prepare students for the jobs that they want. Amid the Covid-19 pandemic, programmes with practical curricula are apparently more vulnerable to the abrupt changes in delivering a successful GGE programme.

- Teacher qualification. Teacher qualification varies substantially among different types of universities. Most highranked research universities recruit faculty members mostly based on research achievements. Many simply have little or no previous teaching experience before they stand at the podium. On the other hand, in undergraduate institutions or community colleges, faculty members have more chances to receive training in state-of-the-art pedagogy and teaching skills. They are likely to be more comfortable to the adjustment to the new norm amid the pandemic.

- Student commitment. The student commitment to academic study is related to their family situations. For instance, students from high-income families are normally fully supported by their families and do not need to take part-time jobs. Thus, students with such background are able to commit full time towards their academic study even during the pandemic when courses are switched online. However, a substantial proportion of students from low-income families have to take multiple part-time jobs. During the pandemic, they are facing more financial pressure and likely to commit even less time in their academic study, which may even lower their aspirations and compel them to drop out the courses. This variation has been noticed at all education levels, as reported by Van Lancker and Parolin (2020) and Dorn et al. (2020).

\section{Faculty contingent measures}

Amid the rapidly developed pandemic situation around the world, the universities and faculty have adopted contingent measures to continue delivering GGE courses (Figure 2(b)). While many of these responses are temporary, and may not be the best practice, 
they can provide the GGE community with some insights into optimising contingent plans in the future in response to a similar public health crisis. This section mainly serves as anecdotal recounts of emergency experiences from GGE faculty members. Following are a couple of inspiring actions implemented or prepared to be implemented by GGE faculty members as part of their contingent measures to enhance teaching and learning experience during the pandemic.

\section{Active learning}

Active learning modules have been increasingly adopted in geotechnical education. There are also well-documented studies regarding how active learning can be effectively promoted in geotechnical engineering (Leung, 2012). In response to the challenges facing GGE education during the pandemic, faculty members are increasingly using active learning. The following are a few examples:

- Small-team problem solving exercises are adopted to virtual teaching using a breakout room feature on the videoconference platform. The instructor assigns random groups and varies the size, depending on the exercise, to promote broad social interactions (otherwise entirely missing in virtual teaching) and learning effectiveness among the students.

- Cross-course teaming exercise. At California Polytechnic State University, a teaming exercise between ENVE 421, Mass Transfer Operations; ENVE 450, Industrial Pollution Prevention; and CE 587, Geoenvironmental Engineering, is conducted. The teams are formed with students from each course to approach a broad geoenvironmental problem in related steps: $(a)$ determine contamination levels in landfill leachate (ENVE 450), (b) determine diffusion characteristics of the selected chemicals (ENVE 421) and (c) design an earthen containment liner to prevent leakage of the selected chemicals (CE 587). The students are responsible for delivering their component of the assignment and contributing to the report prepared by each team. This required student-tostudent teaching and learning across the three courses.

- Enhanced social element of teaching and learning. In one example, the instructor implements a practice of sharing music during the $10 \mathrm{~min}$ break of a $2 \mathrm{~h}$ synchronous lectures. This brings a personal tone and human element to the teaching to engage the students best in the coursework and, unexpectedly, allows exploring diversity and inclusivity aspects in the courses.

\section{New teaching content associated with public health during a pandemic}

- The role of GGE in mitigating Covid-19 impacts on the society is added to existing teaching contents, such as disposal of medical wastes, groundwater decontamination, rapid construction of temporary structures for hospitals and the production of medical supplies (Paleologos et al., 2020; Tang et al., 2020). The construction of the Wuhan
Huoshenshan Hospital in Wuhan, China, is a vivid example to show students how GGE engineers are involved in the global efforts to battle with Covid-19.

- The pandemic-environment interaction is another topic that is included in graduate-level GGE courses. Studies already show that Covid-19 pandemic has led to decreased concentrations of nitrogen dioxide $\left(\mathrm{NO}_{2}\right)$ and $\mathrm{PM}_{2.5}$ in the atmosphere, cleaner beaches and reduced environmental noise level due to lockdown worldwide. On the other hand, it has resulted in an increased load of personal protective equipment and medical wastes, a significant reduction in waste-recycling activities and disinfectant-induced water pollution (ZambranoMonserrate et al., 2020). Therefore, a discussion on the effects of Covid-19 on the environment in a GGE course could help students in realising the issues and challenges associated with recycling of contaminated wastes.

\section{Expanding e-learning resources}

- Virtual field trip and soil mechanics laboratory. Field trip is for long regarded as an effective approach to motivating students and making them aware of the reality in geotechnical engineering practice (Jimenez and Martin-Rosales, 2012). A virtual tour of different geotechnical structures, problematic sites and case studies; assignment of individual projects to the students on geotechnical issues relevant to their locality; and so on are adopted for providing a glimpse of the real-life experience. Although these options cannot replace the actual field experience, these at least may help keep up subject interest among the students. Some faculty members are also developing mobile apps of a virtual soil laboratory, enabling students to learn the operation of soil laboratory tests online and deepen their understanding of GGE subjects.

- E-repository of GGE laboratory sessions. Long before the pandemic started, numerous online resources to support geotechnical laboratory classes have been established (Airey et al., 2012). This pandemic, however, forces GGE faculty members to create more e-resources of laboratory sessions. Enormous new videos of experimentation have been prepared and submitted to e-GGE repositories for future semesters and will remain available after the crisis for distance learning or for students that miss a class during a semester. For instance, the US Universities Council on Geotechnical Education and Research has added a lot more lab videos during the pandemic. The data in the e-GGE repository will be very useful for students to enhance their learning until the university and laboratory reopen.

- Advanced e-learning technologies. Solutions that involve the usage of mixed reality, including virtual reality and augmented reality (Bennett et al., 2017, 2019), and artificial intelligence are being increasingly developed by GGE faculty members during the pandemic to establish an Internet of things where students can conduct their lab work examining a wide range of possibilities and observing the outcomes. For instance, a computer program has been developed that is 
capable of predicting soil triaxial shear behaviour using machine learning (Penumadu et al., 2000).

- E-resources on emerging issues and cross-disciplinary applications. Students' learning experience of GGE can be further enhanced by developing more novel examples related to emerging issues and cross-disciplinary applications (Howell et al., 2020). During the pandemic, GGE faculty members are putting more efforts to develop these e-resources. For instance, monitoring of long-term geoenvironmental phenomena (viz. biodegradation, leachate, gas creation, etc.) that occur in a landfill has been adopted to demonstrate the efficacy of the 'sensing technology' to ascertain their proper functioning. The remote operation of robotics to demonstrate automated construction and monitoring is also incorporated into a GGE course to give students hands-on experience on the cutting-edge technologies being deployed.

\section{Assessment of learning outcome with more student engagement}

- Self-evaluation tests. To improve student engagement, it can be supported by introducing continuous self-evaluation tests and some complex tasks that need interaction with the teacher. Taking some practical examples from the MSc course of Geotechnics for Energy Production in Politecnico di Milano, students have been asked to self-evaluate their theoretical understanding with simple exercises - for example, by extending borehole stability analyses to different failure criteria and by proving that Biot poroelasticity tends to classical soil mechanics under the assumptions of incompressible pore fluid and solid particles.

- Practical homework has also been proposed throughout the course, regarding the choice of rock strength parameters from laboratory data, in situ stress state determination in rock masses, mud weight window determination and offshore foundation design. More complex tasks - where interaction with the teacher is anticipated - have been assigned too - for example, to identify the displacement field induced around a depleting sphere in a linear poroelastic medium.

\section{High-impact integrated GGE education and research}

It has been widely recognised that integrating research into GGE education can provide students with better learning experiences, which are translated into increased understanding of important concepts and greater interest in continued education in GGE (Pierce, 2016; Trombetta et al., 2012). Besides findings from new research are likely to supplement traditional teaching contents and update students with the state of the art and practice (Orlandi and Manzanal, 2020). The pandemic has led to the development of more integration of GGE education and research by faculty members.

During the pandemic, graduate-level GGE courses are being leveraged with cutting-edge GGE research related to pathogeninduced pandemics. For instance, bio-mediated and bio-inspired geotechnics has been a very popular research topic in recent years
(Jiang et al., 2020; Shashank et al., 2016). The knowledge generated in this new area of GGE could be of potential help in modelling pathogen-geoenvironment interactions in a precise manner (Tang et al., 2020). It is possible to incorporate the state-ofthe-art of this new field into a graduate-level GGE course related to geoenvironment or sustainability. Students enrolling in this course will have a chance to get exposed to cutting-edge bio-mediated and bio-inspired geotechnical engineering research, which is the utmost need of the hour. The other example is that recent studies (Paleologos et al., 2020; Tang et al., 2020) have cited the presence of the new coronavirus in sewage sludges and MSW. In this regard, adopting sensor-based technologies for performing some of these investigations - namely, in situ measurement of temperature and moisture content for decompositional characteristics - would be a prudent exercise. In this context, Patil et al. (2017) employed multilevel thermocouples and frequency-domain reflectometry probes to monitor temperature and volumetric moisture content, respectively, at different depths of a bioreactor landfill, which in turn is instrumental in (a) managing leachate recirculation and (b) accelerating the decomposition of MSW. These new monitoring techniques can be integrated into a graduate course focusing on GGE instrumentation.

\section{Lessons learned from faculty contingent measures}

By revisiting the contingent measures taken by GGE faculty members across countries, the following lessons can be learned.

- Remote teaching during the pandemic relies heavily on e-learning resources and pedagogies. While GGE faculty members are fully aware of it, it still takes time, and it may take a long time to fulfill fully the demand for e-learning infrastructures and human resources during the pandemic situation.

- The abrupt switch in teaching and learning mode during the pandemic, on the other hand, is a good opportunity to test and implement newly developed or non-traditional education concepts. Faculty members are more flexible in implementing new pedagogies in an online learning environment.

Administrators are also more willing to support these initiatives.

- The pandemic and coronavirus themselves have made people aware of the importance of human-environment-pathogen interactions, which are largely missing in existing GGE education and research. It thus deserves thinking of expanding interdisciplinary elements in GGE programmes for the future.

\section{Future opportunities}

When it is becoming increasingly clear that people have to live with the virus for an extended period, the GGE faculty members have to define the new norm for GGE education based on existing best practice and experience that they have learned from implementing contingent measures at the early stage of the pandemic. It is also important to use tools and results from engineering education research, although it is acknowledged that large gaps still exist between the findings of engineering education research and engineering teaching practice (Pantazidou, 2016). 
This section mainly presents opinions on the development of better teaching and learning environments for the future when a similar public health crisis unfortunately happens. The following are a few proposed opportunities that can be further explored to define a more resilient, engaged, interactive and technology-based GGE learning environment for students. It should be noted that these identified future opportunities are not necessarily new and may have been previously reported and elaborated by the engineering education community. However, the authors view these as a chance to facilitate greater interactions among GGE faculty and education professionals.

\section{Smart learning}

Smart learning/education is a relatively new education paradigm, which is proposed and developed owing to the rapid progressing of intelligent technologies. While there is no unified definition of smart learning so far, it generally refers to context-aware ubiquitous learning through providing student-centred, personalised and adaptive learning service by adopting interactive and collaborative intelligent tools (Hwang, 2014; Zhu et al., 2016). Tikhomirov et al. (2015) defined the three dimensions of smart learning/education as (a) educational outcomes, (b) information and communication technologies (ICTs) and (c) organisational aspects. The educational outcome dimension reflects the skills that should be acquired through smart education, which include adaptation, awareness, logical reasoning, selflearning, anticipation and self-organisation (Uskov et al., 2018a). The ICT dimension reflects a set of ICT technologies for organising and managing learning progress, developing learning content, facilitating social interaction during the learning process and achieving mobility (Uskov et al., 2016, 2018b). The organisational aspect dimension reflects the flexibility of educational programmes, forms of learning and principles of teaching, including openness, individualism and customisation.

The concept of smart learning has been widely implemented in engineering education. Alelaiwi et al. (2015) reported a case study of delivering a digital signal-processing course in a smart class environment with enhanced learning-management services that include an array of advanced communication technologies. Uskov et al. (2019) developed an innovative InterLabs smart learning analytics system and incorporated it into a computer science and information system curriculum. Sood and Singh (2019) proposed a cloud-computing-based smart learning framework that could enhance students' employability in engineering education. Verma et al. (2017) proposed a smart computing-based student performance evaluation framework and experimentally evaluated it by monitoring the daily activities of computer science and engineering students. In civil engineering education, Zhang and $\mathrm{Lu}$ (2008) presented the education development in the field of smart structure technology and how it was incorporated into an undergraduate civil engineering curriculum. For GGE courses, Jaksa (2020) introduced the use of a $360^{\circ}$ camera and virtual reality to create a smart learning environment and provide relatively authentic immersive experiences to students. Barreto (2012) implemented electronic voting systems (i.e. class response systems) for automatically gathering statistics related to the response of students in geotechnical engineering classes. It has been successfully shown that this method can provide immediate feedback to students and encourage their engagement. Pinho-Lopes (2012) reported how computing and software can be better incorporated into a soil mechanics course to enhance students' understanding of basic concepts as well as soft skills.

While most of the existing smart learning models and strategies focus on enhancing the classroom experience for students, it is also possible to adjust the configurations of heavily deployed ICTs so that they are compatible with a remote learning environment. Further research is strongly recommended in this area.

\section{Flipped learning}

The concept of flipped learning has been increasingly popular in higher education for its potential to engage students better in active learning (Bond, 2020). Based on the collaborative learning theory and constructivism (Bishop and Verleger, 2013), flipped learning provides lecture materials such as slides and handouts to students outside of the classroom, instead of directly teaching these contents at class. During class time, instructors and students will focus primarily on interactive group learning activities (Song and Kapur, 2017). Some researchers also regard out-of-class video components as part of flipped learning (Cheng et al., 2019). In the realm of civil engineering education, flipped learning is also gaining popularity in recent years. For instance, Mojtahedi et al. (2020) piloted a flipped-classroom instructional model in a second-year construction-management class. Yan et al. (2018) established an active flipped-learning model and applied it in an engineering mechanics class. Warren and Padro (2019) trialled a partially flipped-classroom pedagogical model in a geotechnical course to assess student engagement, perceptions, learning and gains. For GGE education, taking a soil remediation course as an example, flipped-learning pedagogy can be implemented by assigning students with the tasks to learn lecture materials related to the principles and features of various soil remediation methods out of class. Then, during class time, instructors and students can focus on several case studies of real soil remediation projects. More recently, Professor M. B. Jaksa from the University of Adelaide particularly introduced how flipped learning can be potentially incorporated into traditional GGE courses when delivering the Second Burland Lecture on Geotechnical Engineering Education in the International Conference on Geotechnical Engineering Education 2020 (Jaksa, 2020).

Due to its nature of moving lecture content before class, flipped learning seems to be an ideal strategy when the whole class has to be delivered remotely during a public health crisis such as the Covid-19 pandemic. However, it should be noted that whether flipped learning can be effectively implemented during the pandemic still depends on students' accessibility to Internet infrastructure as well as the availability of highly interactive communication software (Fung and Lam, 2020). 


\section{Interdisciplinary engineering education}

The concept of interdisciplinary engineering education (IEE) is not new, and its implementation is training future engineers who can work both within and outside the boundaries in their own discipline (Barut et al., 2006). Van den Beemt et al. (2020) proposed a threelevel conceptual framework based on a why-how-what approach to analyse interdisciplinary learning and practice. The three-level educational processes are vision, teaching and support. The vision or motivation of IEE is to train students with complex real-world problem-solving skills, entrepreneurial competencies and social awareness. The primary teaching process of IEE includes encouraging students' participation from different disciplines, applying problem-based and project-based pedagogies to address interdisciplinary issues, creating highly engaged interdisciplinary assignments and developing assessment procedures compatible with interdisciplinary educational contexts. The support for IEE includes training and advice resources for interdisciplinary teaching skills and institutional incentives for interdisciplinary course design.

There have been many reported case studies related to IEE. For instance, McCrum (2017) proposed an interdisciplinary problembased learning strategy to improve creative problem-solving skills in structural engineering students at Queen's University Belfast. Hunt (2018) developed a multidisciplinary civil engineering capstone design project at the University of Nebraska-Lincoln, which originated from an existing industry consulting project. Zhang et al. (2020) developed an interdisciplinary building-informationmodelling-based capstone course in highway engineering at Chang'an University by integrating the design work content of nine different subjects. In the realm of GGE courses, Simpson and Ferentinou (2020) systematically examined the extent to which project-based learning allowed students to develop the reasoning, evaluation and judgement processes required in geotechnical engineering practice at the University of Johannesburg. Dalal et al. (2017) proposed an interdisciplinary approach to develop an undergraduate course on biogeotechnical engineering at Arizona State University. Gavin (2012) implemented hybrid project-based learning to teach geotechnical design skills in the final year of a civil engineering programme at University College Dublin.

A public health crisis such as Covid-19 brings about new opportunities for IEE in GGE. As has been adopted in faculty contingent measures, interdisciplinary teaching contents can be directly exploited from the pandemic. Moreover, the wide adaptation of remote teaching strategies and pedagogies is likely to facilitate the delivery of interdisciplinary contents as well as improve students' engagement. The universities are also more likely to support the development of new interdisciplinary courses that can be delivered remotely.

\section{Closure comments}

The Covid-19 outbreak is a tragedy to higher education worldwide and particularly disrupts GGE education and research, which traditionally heavily rely on hands-on experiences, laboratory experiments and field visits. The key challenge for the faculty members is how to balance the flexibility of learning and physical distancing requirements without compromising learning outcome, education equity and interpersonal interactions in traditional teaching mode. Looking forward, challenges always come with opportunities. Pandemics such as Covid-19 provide the time and impetus to reflect on existing teaching-learning modes and implement changes. Lessons and experience learned from temporary measures in response to the pandemic could help the GGE faculty develop a more resilient, engaged, interactive and technology-based learning environment for students in the near future.

\section{Acknowledgements}

This work was financially supported by National Natural Science Foundation of China (Grant nos. 41877248 and 42007246). The authors thank Mr Yi-Jie Wang and Mr Xiao-Le Han for helping prepare the graphs in the manuscript.

\section{REFERENCES}

Abet (Accreditation Board for Engineering and Technology) (2019) Criteria for Accrediting Engineering Programs. Abet, Baltimore, MD, USA. See https://www.abet.org/wp-content/uploads/2020/03/E001-20-21EAC-Criteria-Mark-Up-11-24-19-Updated.pdf (accessed 01/08/2020). Airey DW, Cafe P and Drury H (2012) The use of online resources to support laboratory classes in soil mechanics. In Shaking the Foundations of Geo-engineering Education: Proceedings of the International Conference on Geotechnical Engineering Education 2012 (McCabe B, Pantazidou M and Phillips D (eds)). Taylor \& Francis, London, UK, pp. 113-120.

Alelaiwi A, Alghamdi A, Shorfuzzaman M et al. (2015) Enhanced engineering education using smart class environment. Computers in Human Behavior 51(Part B): 852-856, https://doi.org/10.1016/j.chb.2014.11.061.

Barreto D (2012) The use of electronic voting systems to enhance deep learning. In Shaking the Foundations of Geo-engineering Education: Proceedings of the International Conference on Geotechnical Engineering Education 2012 (McCabe B, Pantazidou M and Phillips D (eds)). Taylor \& Francis, London, UK, pp. 183-191.

Barut M, Yildirim M and Kilic K (2006) Designing a global multidisciplinary classroom: a learning experience in supply chain logistics management. International Journal of Engineering Education 22(5): 1105-1114.

Bennett V, Abdoun T, Harteveld C, McMartin F and El Shamy U (2017) Classroom implementation of game-based module for geotechnical engineering education. Proceedings of the 124th American Society for Engineering Education Annual Conference and Exposition, Columbus, OH, USA, paper no. 18142 .

Bennett VG, Mbah I, Harteveld C et al. (2019) Off-site implementation of GeoExplorer: a game-based module for geotechnical engineering education. In Geo-Congress 2019: Data, Software, Education, and a Tribute to Ralph Peck (Meehan CL, Kumar S, Pando MA and Coe JT (eds)). American Society of Civil Engineers, Reston, VA, USA, pp. 99-106.

Bishop J and Verleger M (2013) The flipped classroom: a survey of the research. Proceedings of the 120th American Society for Engineering Education Annual Conference and Exposition, Atlanta, GA, USA, paper no. 6219.

Bond M (2020) Facilitating student engagement through the flipped classroom approach in K-12: a systematic review. Computers \& Education 151: article 103819, https://doi.org/10.1016/j.compedu.2020.103819.

Cheng L, Ritzhaupt AD and Antonenko P (2019) Effects of the flipped classroom instructional strategy on students' learning outcomes: a meta-analysis. Educational Technology Research and Development 67(4): 793-824, https://doi.org/10.1007/s11423-018-9633-7. 
Dalal M, Larson J, Zapata C et al. (2017) An interdisciplinary approach to developing an undergraduate module on biogeotechnical engineering. In Proceedings of SITE 2017: 28th International Conference Society for Information Technology and Teacher Education (Resta P and Smith S (eds)). Association for the Advancement of Computing in Education (AACE), Waynesville, NC, USA, pp. 2074-2079.

DeBoer J (2012) Engineering education around the world: a student perspective. Proceedings of the 119th American Society for Engineering Education Annual Conference and Exposition, San Antonio, TX, USA, pp. 17.22.1-17.22.8.

Dorn E, Hancock B, Sarakatsannis J and Viruleg E (2020) COVID-19 and Student Learning in the United States: The Hurt Could Last a Lifetime. McKinsey \& Company, New York, NY, USA. See https:// www.mckinsey.com/ /media/McKinsey/Industries/Public\%20Sector/ Our\%20Insights/COVID19\%20and\%20student\%20learning\%20in\% 20the $\% 20$ United $\% 20$ States $\% 20$ The $\% 20$ hurt $\% 20$ could $\% 20$ last $\% 20 \mathrm{a} \%$ 20lifetime/COVID-19-and-student-learning-in-the-United-StatesFINAL.pdf (accessed 20/07/2020).

Fung FM and Lam Y (2020) How COVID-19 disrupted our 'flipped' freshman organic chemistry course: insights gained from Singapore. Journal of Chemical Education 97(9): 2573-2580, https://doi.org/10. 1021/acs.jchemed.0c00590.

Gavin KG (2012) Use of project based learning to teach geotechnical design skills to civil engineering students. In Shaking the Foundations of Geoengineering Education: Proceedings of the International Conference on Geotechnical Engineering Education (McCabe B, Pantazidou M and Phillips D (eds)). Taylor \& Francis, London, UK, pp. 257-264.

Howell G, Amir E, Barry V et al. (2020) Enriching the geotechnical engineering classroom through novel multidisciplinary examples. In Geo-Congress 2020: Geotechnical Earthquake Engineering and Special Topics (Hambleton JP, Makhnenko R and Budge AS (eds)). American Society of Civil Engineers, Reston, VA, USA, pp. 660-668.

Hunt GA (2018) A case study of interdisciplinary capstone engineering design. Proceedings of the 125th American Society for Engineering Education Annual Conference and Exposition, Salt Lake City, UT, USA, paper no. 22123

Hwang GJ (2014) Definition, framework and research issues of smart learning environments-a context-aware ubiquitous learning perspective. Smart Learning Environments 1(1): article 4, https://doi. org/10.1186/s40561-014-0004-5.

Jaksa MB (2020) Reflections on some contemporary aspects of geotechnical engineering education - from critical state to virtual immersion. In Proceedings of the Online International Conference on Geotechnical Engineering Education 2020 (GEE2020) (Pantazidou M, Calvello M and Lopes MP (eds)). International Society for Soil Mechanics and Geotechnical Engineering, London, UK, pp. 1-16.

Jiang N, Tang C, Hata T et al. (2020) Bio-mediated soil improvement: the way forward. Soil Use and Management 36(2): 185-188, https://doi. org/10.1111/sum.12571.

Jimenez R and Martin-Rosales W (2012) The use of field visits in graduate geotechnical teaching. In Shaking the Foundations of Geo-engineering Education: Proceedings of the International Conference on Geotechnical Engineering Education 2012 (McCabe B, Pantazidou M and Phillips D (eds)). Taylor \& Francis, London, UK, pp. 157-162.

Leung CF (2012) Promoting active learning in geotechnical engineering. In Shaking the Foundations of Geo-engineering Education: Proceedings of the International Conference on Geotechnical Engineering Education 2012 (McCabe B, Pantazidou M and Phillips D (eds)). Taylor \& Francis, London, UK, pp. 273-280.

McCrum DP (2017) Evaluation of creative problem-solving abilities in undergraduate structural engineers through interdisciplinary problembased learning. European Journal of Engineering Education 42(6): 684-700, https://doi.org/10.1080/03043797.2016.1216089.

Mojtahedi M, Kamardeen I, Rahmat H and Ryan C (2020) Flipped classroom model for enhancing student learning in construction education. Journal of Civil Engineering Education 146(2): article05019001, https://doi.org/10.1061/(ASCE)EI.2643-9115. 0000004.

Orlandi S and Manzanal D (2020) Supervised professional practices: research as option to strengthening knowledge in geotechnical practice. In Proceedings of the Online International Conference on Geotechnical Engineering Education 2020 (GEE2020) (Pantazidou M, Calvello M and Lopes MP (eds)). International Society for Soil Mechanics and Geotechnical Engineering, London, UK.

Paleologos EK, O'Kelly BC, Tang C et al. (2020) Post Covid-19 water and waste water management to protect public health and geoenvironment. Environmental Geotechnics, https://doi.org/10.1680/jenge.20.00067.

Pantazidou M (2016) Bridging geotechnical engineering education and research on education. Proceedings of International Conference on Geotechnical Engineering Education 2016 - Shaping the Future of Geotechnical Education, Belo Horizonte, Brazil.

Pantazidou M and Kandris K (2016) Creating an online version of an environmental geotechnics course: pedagogical opportunities. Proceedings of the International Conference on Geotechnical Engineering Education 2016 - Shaping the Future of Geotechnical Education, Belo Horizonte, Brazil.

Patil BS, Agnes AC and Singh DN (2017) Simulation of municipal solid waste degradation in aerobic and anaerobic bioreactor landfills. Waste Management \& Research 35(3): 301-312, https://doi.org/10.1177/ $0734242 X 16679258$.

Penumadu D, Zhao R and Frost D (2000) Virtual geotechnical laboratory experiments using a simulator. International Journal for Numerical Methods in Engineering 24(5): 439-451, https://doi.org/10.1002/ (SICI)1096-9853(20000425)24:5<439::AID-NAG74>3.0.CO;2-G.

Pierce CE (2016) Problem-based learning with EFFECTs: part I preparing future faculty to integrate teaching and research - SFGE 2016. Proceedings of the International Conference on Geotechnical Engineering Education 2016 - Shaping the Future of Geotechnical Education, Belo Horizonte, Brazil.

Pinho-Lopes M (2012) Implementation of the use of computing and software in undergraduate soil mechanics courses. In Shaking the Foundations of Geo-engineering Education: Proceedings of the International Conference on Geotechnical Engineering Education 2012 (McCabe B, Pantazidou M and Phillips D (eds)). Taylor \& Francis, London, UK, pp. 193-200.

Semaan B (2020) Restoring Security When Disruption Becomes the Routine. Syracuse University School of Information Studies, Syracuse, NY, USA. See https://ischool.syr.edu/life-in-the-time-of-covid-19restoring-security-when-disruption-becomes-the-routine/ (accessed date 08/08/2020).

Shashank BS, Sharma S, Sowmya S et al. (2016) State-of-the-art on geotechnical engineering perspective on bio-mediated processes. Environmental Earth Sciences 75(3): article 270, https://doi.org/10. 1007/s12665-015-5071-6.

Simpson Z and Ferentinou M (2020) Lessons learned about engineering reasoning through projectbased learning: an ongoing action research investigation. In Proceedings of the Online International Conference on Geotechnical Engineering Education 2020 (GEE2020) (Pantazidou M, Calvello M and Lopes MP (eds)). ISSMGE, London, UK.

Song Y and Kapur M (2017) How to flip the classroom - 'productive failure or traditional flipped classroom' pedagogical design? Educational Technology and Society 20(1): 292-305.

Sood SK and Singh KD (2019) Optical fog-assisted smart learning framework to enhance students' employability in engineering education. Computer Applications in Engineering Education 27(5) 1030-1042, https://doi.org/10.1002/cae.22120.

Tang CS, Paleologos EK, Vitone C et al. (2020) Environmental geotechnics: challenges and opportunities in the post-COVID-19 world. Environmental Geotechnics, https://doi.org/10.1680/jenge.20. 00054 . 
Geotechnical and geoenvironmental engineering education during the pandemic

Jiang, Hanson, Della Vecchia et al.
Tikhomirov V, Dneprovskaya N and Yankovskaya E (2015) Three dimensions of smart education. In Smart Education and Smart eLearning (Uskov VL, Howlett R and Jain L (eds)). Springer, Cham, Switzerland, pp. 47-56.

Trombetta NW, Fiegel GL and Mason HB (2012) Learning through doing: using geotechnical research to prepare undergraduates for graduate school. In Shaking the Foundations of Geo-engineering Education: Proceedings of the International Conference on Geotechnical Engineering Education 2012 (McCabe B, Pantazidou M and Phillips D (eds)). Taylor \& Francis, London, UK, pp. 309-316.

Uskov V, Pandey A, Bakken JP and Margapuri VS (2016) Smart engineering education: the ontology of Internet-of-Things applications. In IEEE EDUCON Global Engineering Education Conference: Proceedings of the Tenth IEEE Global Engineering Education Conference (EDUCON 2019). Institute of Electrical and Electronics Engineers, Piscataway, NJ, USA, pp. 476-481.

Uskov V, Bakken JP, Aluri L et al. (2018a) Smart pedagogy: innovative teaching and learning strategies in engineering education. Proceedings of the 2018 IEEE World Engineering Education Conference (EDUNINE), Buenos Aires, Argentina, pp. 1-6.

Uskov V, Bakken JP, Shah A et al. (2018b) Software/hardware systems and technology for smart engineering education. Proceedings of the 2018 IEEE World Engineering Education Conference (EDUNINE), Buenos Aires, Argentina, pp. 1-6.

Uskov VL, Bakken JP, Shah A et al. (2019) Innovative InterLabs system for smart learning analytics in engineering education. In IEEE EDUCON Global Engineering Education Conference: Proceedings of the Tenth IEEE Global Engineering Education Conference (EDUCON 2019) (Ashmawy AK and Schreiter S (eds)). Institute of Electrical and Electronics Engineers, Piscataway, NJ, USA, pp. 1363-1369.

Van den Beemt A, MacLeod M, Van der Veen J et al. (2020) Interdisciplinary engineering education: a review of vision, teaching, and support. Journal of Engineering Education 109(3): 508-555, https://doi.org/10.1002/jee.20347.

Van Lancker W and Parolin Z (2020) COVID-19, school closures, and child poverty: a social crisis in the making. Lancet Public Health 5(5): 243-244, https://doi.org/10.1016/S2468-2667(20)30084-0.
Verma P, Sood SK and Kalra S (2017) Smart computing based student performance evaluation framework for engineering education. Computer Applications in Engineering Education 25(6): 977-991, https://doi.org/10.1002/cae.21849.

Warren K and Padro M (2019) Design and preliminary data from a partially flipped classroom (PFC) study in a geotechnical engineering course. Proceedings of the 126th American Society for Engineering Education Annual Conference, Tampa, FL, USA, paper no. 25602.

WHO (World Health Organization) (2020m) COVID-19 Weekly Epidemiological Update-8 December 2020. WHO, Geneva, Switzerland. See https://www.who.int/publications/m/item/weeklyepidemiological-update-8-december-2020 (accessed 12/12/2020).

Wirth X, Jiang N, da Silva T et al. (2017) Undergraduate geotechnical engineering education of the 21 st century. Journal of Professional Issues in Engineering Education and Practice 143(3): article 02516002, https://doi.org/10.1061/(ASCE)EI.1943-5541.0000317.

Yan J, Nie Y, Li L and Yin J (2018) Preliminary study of active flipped learning in engineering mechanics. Proceedings of the 125th American Society for Engineering Education Annual Conference and Exposition, Salt Lake City, UT, USA, paper no. 21687. See https://peer.asee.org/ 30122 (accessed 20/03/2021).

Zambrano-Monserrate MA, Ruano M and Sanchez-Alcalde L (2020) Indirect effects of COVID-19 on the environment. Science of the Total Environment 728: article 138813, https://doi.org/10.1016/j.scitotenv. 2020.138813

Zhang Y and Lu LW (2008) Introducing smart structures technology into civil engineering curriculum: education development at Lehigh University. Journal of Professional Issues in Engineering Education and Practice 134(1): 41-48, https://doi.org/10.1061/(ASCE)1052-3928 (2008)134:1(41).

Zhang J, Zhao C, Li H, Huijser H and Skitmore M (2020) Exploring an interdisciplinary BIM-based joint capstone course in highway engineering. Journal of Civil Engineering Education 146(3): article 05020004, https://doi.org/10.1061/(ASCE)EI.2643-9115.0000017.

Zhu ZT, Yu MH and Riezebos P (2016) A research framework of smart education. Smart Learning Environments 3(1): article 4, https://doi. org/10.1186/s40561-016-0026-2.

\section{How can you contribute?}

To discuss this paper, please submit up to 500 words to the editor at journals@ice.org.uk. Your contribution will be forwarded to the author(s) for a reply and, if considered appropriate by the editorial board, it will be published as a discussion in a future issue of the journal. 